Table III.-Readings of Experimental Mrxtures of Methyl and Ethyl AlCOHOLS.

\begin{tabular}{|c|c|c|c|c|c|c|}
\hline \multirow[b]{2}{*}{$\begin{array}{l}\text { Sp. gr. } \\
{ }_{15}^{\circ} \mathrm{C} .\end{array}$} & \multirow[b]{2}{*}{$\begin{array}{l}\text { Percent. } \\
\text { alcohol by } \\
\text { weight. }\end{array}$} & \multirow[b]{2}{*}{$\begin{array}{l}\text { Scale } \\
\text { reading. } \\
20^{\circ} \mathrm{C} \text {. }\end{array}$} & \multicolumn{2}{|c|}{ Methyl alcohol. } & \multicolumn{2}{|c|}{ Ethyl alcohol. } \\
\hline & & & $\begin{array}{l}\text { As } \\
\text { prepared. } \\
\text { Per cent. }\end{array}$ & $\begin{array}{c}\text { As } \\
\text { found. } \\
\text { Per cent. }\end{array}$ & $\begin{array}{l}\text { As } \\
\text { prepared. } \\
\text { Per cent. }\end{array}$ & $\begin{array}{c}\text { As } \\
\text { found. } \\
\text { Per cent }\end{array}$ \\
\hline 0.8190 & 9 I. 36 & $33 \cdot 9$ & 68.52 & 69.88 & 22.84 & 21.48 \\
\hline 0.8190 & $91 \cdot 36$ & 54.9 & 45.68 & $47 \cdot 4 I$ & 45.68 & 44.95 \\
\hline 0.9239 & $47 \cdot 4 \mathrm{I}$ & 51.9 & 35.56 & 35. & $11 . S_{5}$ & II. 99 \\
\hline 0.8190 & $91 \cdot 36$ & 76.3 & 22.84 & $23 \cdot 75$ & 68.52 & 67.61 \\
\hline 0.9326 & $43 \cdot 43$ & 62.4 & $2 \mathrm{I} \cdot 7 \mathrm{I}$ & 21.38 & $22.7 \mathrm{I}$ & 22.05 \\
\hline 0.9643 & 25.64 & 37.2 & 19.23 & $19 \cdot 76$ & $6 .+\mathrm{I}$ & 5.88 \\
\hline 0.9207 & 48.86 & 77.5 & 12.21 & I 1.77 & 36.65 & 37.09 \\
\hline 0.9753 & 17.00 & 34.0 & 8.50 & 8.92 & 8.50 & 8.08 \\
\hline 0.9666 & 23.92 & 50.2 & $5 \cdot 98$ & 6.48 & 17.94 & 17.44 \\
\hline
\end{tabular}

\title{
SOME OBSERVATIONS ON THE DEPOSITION OF ALLOYS FROM MIXED SOLUTIONS. ${ }^{1}$
}

BY ChaRles B. JaCOBS.

Received June IT, 5905 .

RECENTLY the writer had occasion to make a simultaneous deposition of two metals, zinc and nickel, under conditions in which it was impossible to use any of the well-known methods.

The current strength permitted could not be great enough to preverit secondary action of the electropositive metal on the solution of the other, for it would then have resulted in a pulverulent deposit, and the physical structure of the deposit required prohibited anything but a strongly adherent, finely crystalline metal. Neither could cyanide solutions or alkaline solutions of any kind be used, as the deposited alloy was intended to receive a lithographic transfer, and any trace of cyanide solution or alkali acted on the transfer ink and destroyed the fine dots and lines of the work. If the deposited metal were washed sufficiently to rid it of the last traces of cyanide or alkali it became oxidized in spots. These oxidized spots refused to permanently hold the ink from the transfer paper.

Moreover, the composition of the alloy required did not permit of having a small proportion of the more electronegative metal in the bath.

It therefore became necessary to devise a means of plating zinc and nickel simultaneously without the use of cyanide solu-

1 Read at the Buffalo Meeting of the American Chemical Society. 
tions, without maintaining an abnormal current density and with a comparatively large amount of zinc, the electronegative metal, present in the solution.

It soon became apparent that neutral sulphate solutions of zinc and nickel were the ones most suitable for the purpose, to which we found we might add varying proportions of ammonium sulphate and ammonium chloride to aid in regulating the internal resistance of the bath.

The question of anodes was next taken into consideration. An attempt was made to have anodes of zinc and nickel cast of the desired composition for the alloy. This was frustrated on account of the high melting-point of the nickel and the impossibility of obtaining uniform results in the casting. Double anodes were then tried, one of zinc and one of nickel as pure as could be obtained. This worked fairly well for a short time, but a wide departure from the original alloy deposited soon made itself apparent. On examination of the bath and the deposited metal both were found to be running very much higher in nickel than was intended, with a corresponding deficiency in zinc.

Without going into the details of the failures of the many schemes proposed for maintaining the correct proportions of nickel and zinc in our baths, and consequently in our deposited metal, I will only say that it required the better part of six months to solve the problem and reduce it to commercial practice.

A careful consideration of the fundamental laws governing electrolysis with respect to the deposition of metals and a practical application of these laws to fit our peculiar conditions, finally led to the commercial solution of the problem. Since the anodes and the deposited metal were of the same composition we were limited in the electromotive force of the plating bath only by the current density that the cathode surface would stand without yielding a bad deposit.

The consecutive separation of metals from mixed solutions in the ascending scale of their electropositiveness, however, was our chief difficulty. Since there is a difference of voltage necessary to decompose the nickel and zinc salts amounting to about 0.35 of a volt in favor of the nickel, it was impossible at the same voltage to prevent the nickel from increasing in amount both in 
the bath and in the deposit. This very difficulty gave the clue to the solution of the problem.

The electrochemical equivalents show that 1.0994 grams of nickel and I.2II 2 grams of zinc are deposited per hour by a current of I ampere, and it follows from Ohm's law that the strength of current in amperes depends on the electromotive force between the cathode and the anodes.

It only remained to find a method of maintaining the proper difference in voltage between the two anodes and the cathode to have a perfect regulation of the amount of the two metals deposited on the cathode. This was accomplished by the use of two generators running at different voltages, one for the zinc and one for the nickel anode, the current returning through the cathode in the bath by a common third leg to the generators. The plating baths happened to be so designed as to lend themselves readily to the scheme. The inside dimensions of the baths were 72 inches in length, 36 inches in width, and 22 inches in depth. The cathode surface was composed of a copper tube $3^{\frac{1}{2}}$ inches in diameter and 60 inches long. It was fastened to a pair of contact heads directly in the center of the ends of the bath. These heads revolved with the tube at the rate of 2 to $2 \frac{1}{2}$ revolutions per minute.

The circuit from the generators to the bath and return was as shown in the sketch.

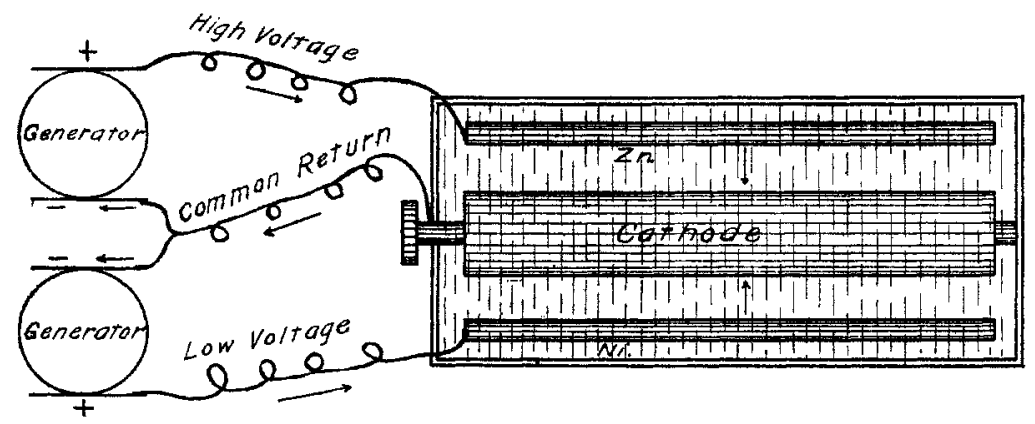

This arrangement made it possible to hang the zinc anode on one side and nickel anode on the other of the revolving cathode and place them at variable distance, in order to regulate the internal resistance of the bath between the cathode and either anode. 
On account of the tendency of the nickel to deposit at lower voltage and also for the reason that a greater proportion of zinc than nickel was required in the alloy, the generator on the zinc side was run at the high voltage.

It was now possible to find the voltage which in relation to the internal resistance of the bath would give the proper relative proportions of zinc and nickel in the deposit, with no more than the ordinary proper attention required in the care of any platingbath to keep these relative proportions fixed.

Sixteen plating-baths of the dimensions given above were equipped with this method which, whether correctly named or not, became known as the "Three Phase Plating System."

In the commercial equipment of the plating-room three sets of bus bars were run along the wall. All the zinc anodes were tapped into the high voltage bar and all of the nickel anodes into the low voltage bar, while the cathodes were all led to the common third bar returning to the generators.

Plating on sheets of metal as well as on the copper tubes was carried out by this method. Sheets of zinc 60 inches by 45 inches were strapped around a revolving cathode by means of clamps and turn buckles and a deposit of nickel and zinc thrown upon them. The metal was reguline, firmly adherent, and showed no tendency to peel or crack, after the sheets were taken off the cathode and laid out straight.

The general commercial application of this method of depositing two metals simultaneously upon the same cathode has not been investigated to any great extent beyond the deposition of nickel and zinc.

Some experiments were made on a small scale in the deposition of copper and zinc from sulphate solutions and a composition was obtained which gave a very good-looking quality of yellow brass.

With a cyanide solution, however, and an anode of copper on the low voltage side and zinc on the high side, some very excellent results were obtained on sheets 60 inches by 45 inches. The regulation in the color of the brass was almost perfect, as it was only necessary to fluctuate the voltage on either side to vary the color from a reddish brass running high in copper to a very light brass running high in zinc.

This method offers a much simpler means of regulation of 
color and composition than is possible with a brass anode. It also makes it possible to produce from the same bath a great variety of color and composition in brassing work.

\title{
THE CHEMISTRY OF ORE DEPOSITION-PRECIPITA= TION OF COPPER BY NATURAL SILICATES. ${ }^{1}$
}

\author{
BY EUGeNe C. SUlLivaN.
}

Received May 27, 1905.

WORK recently done in the chemical laboratory of the United States Geological Survey shows that natural silicates and especially feldspars enter into reactions of double decomposition with salt solutions at ordinary temperatures more readily than is generally recognized, and it appears possible that not only the importance of feldspars, estimated to make up 60 per cent. by weight of the lithosphere, ${ }^{2}$ as precipitants in geological reactions, but also the great superiority of salt solutions over water as disintegrating agents, have not been sufficiently emphasized.

The work in question has suffered interruption for the present, and it is thought desirable to present in very brief outline, at this time, some of the results thus far obtained.

Lemberg ${ }^{3}$ showed that sodium chloride solution at ordinary temperature transformed leucite $\left(\mathrm{KAlSi}_{2} \mathrm{O}_{6}\right)$ partly into analcite $\left(\mathrm{NaAlSi}_{2} \mathrm{O}_{e} \cdot \mathrm{H}_{2} \mathrm{O}\right)$, sodium being substituted for the equivalent quantity of potassium. The reverse substitution took place when analcite was treated with potassium chloride solution.

The reaction

$$
\mathrm{KAlSi}_{2} \mathrm{O}_{8}+\mathrm{NaCl}+\mathrm{H}_{2} \mathrm{O} \leftrightarrows \mathrm{NaAlSi}_{2} \mathrm{O}_{6} \cdot \mathrm{H}_{2} \mathrm{O}+\mathrm{KCl}
$$

is similar to the familiar one

$$
\mathrm{BaSO}_{4}+\mathrm{Na}_{2} \mathrm{CO}_{3} \leftrightarrows \mathrm{BaCO}_{3}+\mathrm{Na}_{2} \mathrm{SO}_{4}
$$

Provided the mass law holds, equilibrium sets in when the concentrations of the substances have the following relation (formulas in brackets indicate concentrations):

$$
\left[\mathrm{KAlSi}_{2} \mathrm{O}_{6}\right] \cdot[\mathrm{NaCl}] \cdot\left[\mathrm{H}_{2} \mathrm{O}\right]=k\left[\mathrm{NaAlSi} \mathrm{O}_{6} \cdot \mathrm{H}_{2} \mathrm{O}\right] \cdot[\mathrm{KCl}] \text {, }
$$

$k$ being the equilibrium constant. As the silicates are both present as solids, their active mass is constant, as is also that of the

- Published by permission of the Director of the United States Geological Survey.

2 F. W. Clarke : Bulletin U. S. Geol. Survey 228, p. 20.

3 Z. deutsch. geolog. Ges., 28,537 (1876). 